\title{
A comparative study on awareness about tuberculosis among urban and rural P.U. college students of Davangere taluk, Karnataka, India
}

\section{Dayalaxmi Tukaram Shedole ${ }^{1 *}$, Shubha Bakkappa Devalgi ${ }^{1}$, Vidya GS ${ }^{2}$, Roopa R. Mendagudli ${ }^{3}$, Vijaya B. Kumar ${ }^{4}$}

\author{
${ }^{1}$ Department of Community Medicine, J. J. M Medical College, Davangere, Karnataka, India \\ ${ }^{2}$ Department of Community Medicine, J. J. M Medical College, Davangere, Karnataka, India \\ ${ }^{3}$ Department of Community Medicine, KBN Institute of Medical Sciences, Kalaburagi, Karnataka, India \\ ${ }^{4}$ Department of Community Medicine, Oxford Institute of Medical Sciences, Bengaluru, Karnataka, India
}

Received: 17 August 2015

Accepted: 22 August 2015

\author{
*Correspondence: \\ Dr. Dayalaxmi T. Shedole, \\ E-mail: dayalaxmi83@gmail.com
}

Copyright: ( $)$ the author(s), publisher and licensee Medip Academy. This is an open-access article distributed under the terms of the Creative Commons Attribution Non-Commercial License, which permits unrestricted non-commercial use, distribution, and reproduction in any medium, provided the original work is properly cited.

\begin{abstract}
Background: Tuberculosis continues to be a major public health problem in our country and is the largest cause of loss of healthy life years in the productive age. Revised National Tuberculosis Control Programme depends on passive reporting of the chest symptomatic to the health institution. Therefore, it is important that the basic knowledge about the disease and the availability of free treatment is clear among the individual in the community.

Methods: A cross sectional study was conducted among 360 students of I and II PU College students of urban and rural area of Davangere Taluk, Karnataka. Selection of schools and students was done by simple random and systematic random sampling method. Data collection was done by using predesigned, pretested structured proforma \& analyzed by using software SPSS version 17.

Results: Our study results show that awareness with regard to severity (64.4\%), causative agent $(72.8 \%)$, whether spreads from person to person $(56.7 \%)$, mode of transmission(38.9\%), symptoms $(78.9 \%)$ and whom to consult if signs of TB are detected $(82.8 \%)$ of rural students was better compared to urban students and with regards to affected organ $(72.8 \%)$, among whom TB is commonly seen $(85 \%)$, diagnosis $(78.9 \%)$, whether TB is curable $(73.3 \%)$, availability of diagnostic and treatment facilities $(71.7 \%)$, prevention $(85 \%)$ and what advice given to TB patient $(86.1 \%)$ awareness was better among urban students compared to rural students.

Conclusions: Our study findings indicated that overall the awareness was better among urban students compared to rural students \& $53 \%$ of the rural students had wrong knowledge that TB can be diagnosed by blood test.
\end{abstract}

Keywords: Pulmonary Tuberculosis, Awareness, PU college students

\section{INTRODUCTION}

Tuberculosis (TB) remains a major public health problem in India. World Tuberculosis Day is observed on 24 March of every year and is designed to build the public awareness about TB as an epidemic. In India two TB patients are loosing their life in every three minutes; nearly 3 lakh School children give up study because of TB per year. Tuberculosis is a barrier to socioeconomic development. The greatest burden of tuberculosis incidence and mortality in India is in adults aged 15-16 years \& higher prevalence seen in persons aged 60 years and above while lowest in childhood, Which may be due to decrease immunity in old age people. ${ }^{1}$

Tuberculosis is a disease of great significance in India. With the advent of the HIV/AIDS epidemic the problem has been compounded. The Millennium Development Goal number 6 , target 8 , is 'Halt and begin to reverse the incidence of TB by 2015 '. In order to achieve this goal 
the World Health Organization (WHO) launched the Stop TB program; one of the important strategies of which was education and empowerment of communities. ${ }^{2}$

Globally there were an estimated 9.4 million incident cases of T.B with 11.1 million prevalent cases. In 2008, 1.8 million deaths resulted from T.B. India is a highest T.B burden country accounting for $20 \%$ of global burden of tuberculosis,2/3rd of the cases are in SEAR. Every year about 1.8 million persons develop T.B. Two out of every five Indians are infected with T.B bacillus. Patients with infectious pulmonary T.B can infect $10-15$ persons in a year. ${ }^{3}$

T.B continues to rank among world's most serious health problems despite effective diagnostic \& treatment measures. ${ }^{4}$ Current study was conducted considering the fact that unless the general public \& young generation possess basic knowledge about T.B \& its management, it is unlikely to make best use of available facilities.

We have hardly any data from our country, both urban \& rural areas, as to how knowledgeable are our college students about different aspects of tuberculosis. It is hypothesized that improving the knowledge and awareness about tuberculosis in college going children will spread the awareness in the general community. In this study P.U college students are selected as they are more receptive $\&$ are capable of spreading awareness among general population

\section{Objectives:}

1. To assess the awareness about T.B among P.U college students

2. To compare the awareness about T.B among urban \& rural P.U students.

\section{METHODS}

Source of data: I \& II year Government P.U College Students of urban \& rural areas of Davangere taluk,

\section{Method of collection of data:}

\section{Sampling procedure:}

There are about 50 urban \& 19 rural government P.U colleges in Davangere taluk. $10 \%$ of the colleges were selected by simple random sampling method i.e 5 from urban \& 2 from rural area. The sample size was calculated by taking the prevalence that $50 \%$ of students were aware about the exact mode of transmission of T.B from Nepalese study. ${ }^{5}$ The sample is calculated by using formula, $\mathrm{N}=4 \mathrm{pq} / \mathrm{d}^{2}$

Where,

$\mathrm{N}=$ sample size

$\mathrm{p}=$ prevalence of T.B i.e. $50 \%$ $\mathrm{q}=100-\mathrm{p}=100-50=50$

$\mathrm{d}=$ admissible error $(15 \%$ of $\mathrm{p})=15 \%$ of $50=7.5$

$\mathrm{N}=4 \times 50 \times 50 / 7.5 \times 7.5=177.77$

The calculated sample size is 177.8 . It is rounded up to 180 for urban \& 180 for rural areas, thus constituting a total of 360 P.U college students as the study group. It was planned to include only those students for analysis who had replied to the question "Have you ever heard of tuberculosis" in affirmative.174 male students and 186 female students i.e. a total of 360 students who answered in affirmative were eligible for further analysis in this study. Students were selected by systematic random sampling method. Prior permission was obtained from the school authorities. The students were briefed regarding the purpose of the study \& confidentiality maintained. The data was collected by distribution of pre-designed, pre-tested, multiple response type of questionnaire in local language. The questionnaire was addressed on topic of source of information, awareness about T.B which included variables like affected organ, causative agent, who will be affected, whether spreads from person to person \& mode of transmission, its clinical features, diagnosis, treatment \& prevention. Each participant was given a questionnaire \& was instructed to circle the correct answer they know. Every question has a response of right answer, a wrong answer \& don't know also, considering it as incorrect .The forms were collected soon after it is filled up.

Study design: It is a college based cross sectional comparative study.

Study period: 2 months from 1st July, 2012 to 31 st August, 2012.

Statistical analysis: proportions \& chi-square test.

\section{Inclusion criteria:}

a) I \& II year P.U college students of urban \& rural area of Davangere Taluk.

b) Those students who were present on the day of study.

c) Those willing to participate.

\section{Exclusion criteria:}

a) Those students who are absent on the day of data collection

b) Those not willing to participate.

\section{RESULTS}

Figure 1 shows that $144(80 \%)$ students from urban area $\& 120(66.7 \%)$ students from rural area are in the age group of $17 \mathrm{yrs}$. And $36(20 \%)$ students from urban area $\&$ $60(33.3 \%)$ from rural area are in the age group of $18 \mathrm{yrs}$. From figure 2 it is seen that about $128(71 \%)$ students from urban and 46(26\%) students from rural area are males where as 52(29\%) students from urban area and $134(74 \%)$ students from rural area are females. Figure 3 
shows that the main source of information for the area is mass media $(32.8 \%, 52.8 \%)$.

students of urban area is teachers $(38.9 \%)$ and for rural

Table 1: Awareness about epidemiological determinants.

\begin{tabular}{|c|c|c|c|c|}
\hline Sl.no & Variables & $\operatorname{Urban}(n=180)$ & $\operatorname{Rural}(\mathrm{n}=180)$ & $X^{2}$, df, p-value \\
\hline \multirow[t]{4}{*}{1} & TB is severe disease & & & \\
\hline & A. yes & $113(62.8 \%)$ & $116(64.4 \%)$ & $X^{2}=7.66, d f=2, p=0.022$ \\
\hline & B. no & $38(21.1 \%)$ & $21(11.7 \%)$ & \\
\hline & C. don't know & $29(16.1 \%)$ & $43(23.9 \%)$ & Significant \\
\hline \multirow[t]{5}{*}{2} & Most commonly affected organ & & & \\
\hline & A. Heart & $6(3.3 \%)$ & $16(8.9 \%)$ & $X^{2}=25.288, d f=3, p=0.000$ \\
\hline & B. lungs & $131(72.8 \%)$ & $85(47.2 \%)$ & \\
\hline & C. brain & $14(7.8 \%)$ & $30(16.7 \%)$ & Highly significant \\
\hline & D. don't know & $29(16.1)$ & $49(27.2 \%)$ & \\
\hline \multirow[t]{5}{*}{3} & Causative agent & & & \\
\hline & A. Bacteria/germ & $108(60 \%)$ & $131(72.8 \%)$ & $X^{2}=15.69, d f=3, p=0.001$ \\
\hline & B. curse of god & $3(1.7 \%)$ & $0(0 \%)$ & \\
\hline & C. polluted water & $53(29.4 \%)$ & $26(14.4 \%)$ & Highly significant \\
\hline & D. don't know & $16(8.9 \%)$ & $23(12.8 \%)$ & \\
\hline \multirow[t]{5}{*}{4} & T.b commonly seen among & & & \\
\hline & A.anyone including you \& me & $153(85 \%)$ & $137(76.1 \%)$ & $X 2=13.752, d f=3, p=0.003$ \\
\hline & B.only children & $3(1.7 \%)$ & $8(4.4 \%)$ & \\
\hline & C.only old aged individuals & $12(6.7 \%)$ & $5(2.8 \%)$ & Highly significant \\
\hline & D.dont know & $12(6.7 \%)$ & $30(16.7 \%)$ & \\
\hline \multirow[t]{4}{*}{5} & Sreads from person to person & & & \\
\hline & A.yes & $87(48.3 \%)$ & $102(56.7 \%)$ & $X^{2}=4.532, d f=2, p=0.104$ \\
\hline & B.no & $69(38.3 \%)$ & $50(27.8 \%)$ & \\
\hline & C.dont know & $24(13.3 \%)$ & $28(15.6 \%)$ & Not significant \\
\hline \multirow[t]{5}{*}{6} & Mode of transmission & & & \\
\hline & A.droplet infection & $58(32.2 \%)$ & $70(38.9 \%)$ & $X^{2}=4.603, d f=3, p=0.203$ \\
\hline & B.mosquito bite & $21(11.7 \%)$ & $29(16.1 \%)$ & \\
\hline & C.blood transfusion & $61(33.9 \%)$ & $49(27.2 \%)$ & Not significant \\
\hline & D.dont know & $40(22.2 \%)$ & $32(17.8 \%)$ & \\
\hline
\end{tabular}

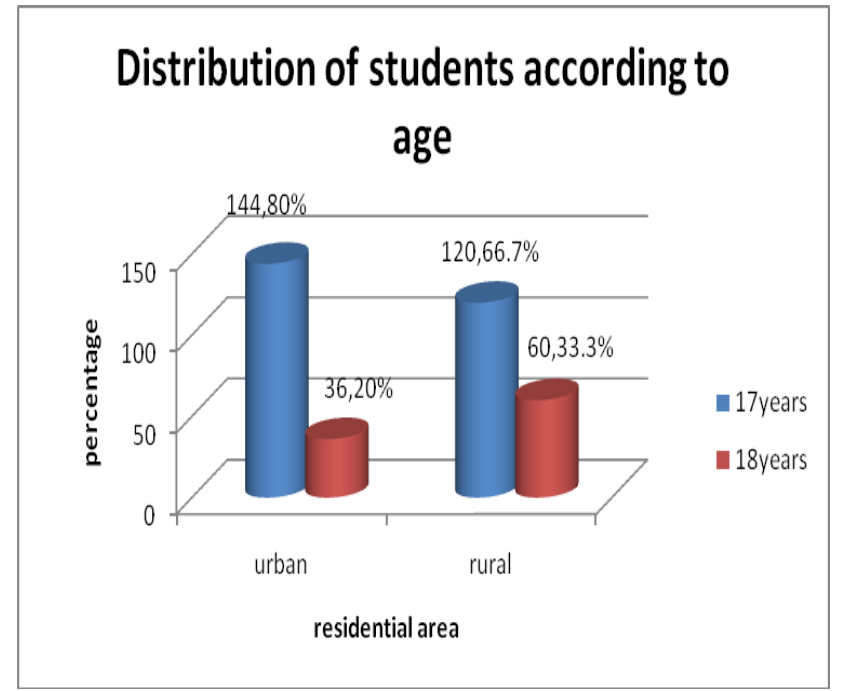

Figure 1: Distribution of students according to age.

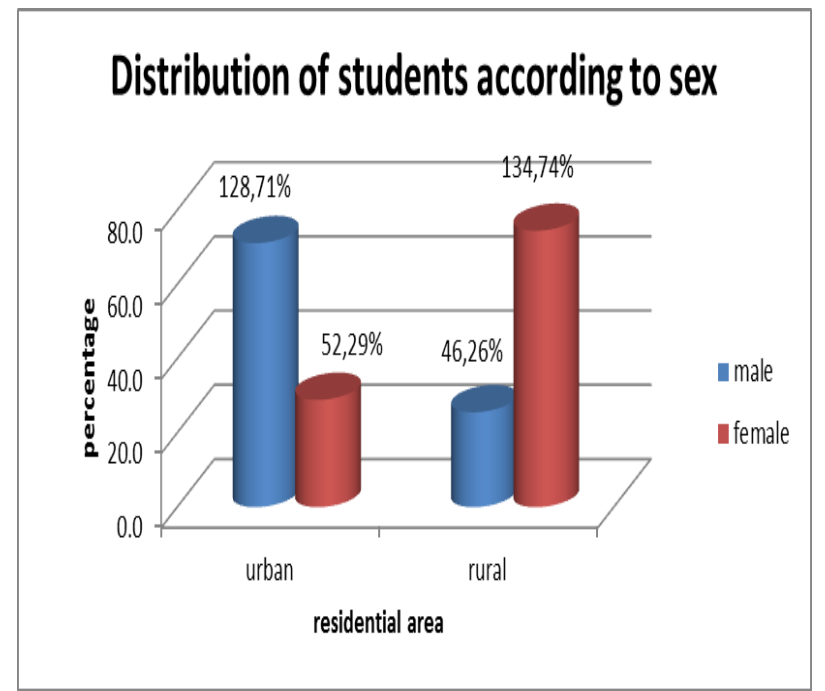

Figure 2: Distribution of students according to sex. 
Table 2: Awareness about symptoms \& diagnosis of tuberculosis.

\begin{tabular}{|lllll|}
\hline Sl.no & Variables & Urban(n=180) & Rural $(\mathbf{n}=180)$ & $\mathbf{X}^{2}, \mathbf{d f}, \mathbf{p}$-value \\
\hline 1 & Symptoms & & & \\
\hline & $\begin{array}{l}\text { A.cough with } \\
\text { expectoration }\end{array}$ & $140(77.8 \%)$ & $142(78.9 \%)$ & $\mathrm{X}^{2}=4.974, \mathrm{df}=3, \mathrm{p}=0.174$ \\
\hline & B.vomiting & $15(8.3 \%)$ & $6(3.3 \%)$ & \\
\hline & C.joint pain & $11(6.1 \%)$ & $12(6.7 \%)$ & Not significant \\
\hline & D.dont know & $14(7.8 \%)$ & $20(11.1 \%)$ & \\
\hline 2 & T.b detected by & & & \\
\hline & A.blood test & $61(33.9 \%)$ & $95(52.8 \%)$ & $\mathrm{X}^{2}=13.381, \mathrm{df}=3, \mathrm{p}=0.004$ \\
\hline & B.urine test & $15(8.3 \%)$ & $10(5.6 \%)$ & \\
\hline & C.sputum test & $89(49.4 \%)$ & $62(34.4 \%)$ & Highly significant \\
\hline & D.dont know & $15(8.3 \%)$ & $13(7.2 \%)$ & \\
\hline
\end{tabular}

Table 3: Awareness about management of tuberculosis.

\begin{tabular}{|c|c|c|c|c|}
\hline Sl.no & Variables & $\operatorname{Urban}(\mathrm{n}=18)$ & Rural(n=180) & $X^{2}$, df, p-value \\
\hline \multirow[t]{4}{*}{1} & Can tb be cured completely & & & \\
\hline & A.yes & $132(73.3 \%)$ & $123(68.3 \%)$ & $\mathrm{X}^{2}=1.177, \mathrm{df}=2, \mathrm{p}=0.555$ \\
\hline & B.no & $18(10 \%)$ & $23(12.8 \%)$ & \\
\hline & C.dont know & $30(16.7 \%)$ & $34(18.9 \%)$ & Not significant \\
\hline \multirow[t]{6}{*}{2} & Treatment $\&$ diagnosis for t.b is & & & \\
\hline & Available in & & & \\
\hline & A.only in govt. Hospitals & $32(17.8 \%)$ & $16(8.9 \%)$ & $X^{2}=16.952 \mathrm{df}=3, p=0.001$ \\
\hline & B.only in private hospitals & $7(3.9 \%)$ & $22(12.2 \%)$ & \\
\hline & C.all govt. Hospitals including Phc's & $129(71.7 \%)$ & $119(66.1 \%)$ & Highly significant \\
\hline & D.dont know & $12(6.7 \%)$ & $23(12.8 \%)$ & \\
\hline \multirow[t]{4}{*}{3} & T.b treatment $\&$ diagnosis is free of cost & & & \\
\hline & A.yes & $92(51.1)$ & $73(40.6 \%)$ & $\mathrm{X}^{2}=7.536, \mathrm{df}=2, \mathrm{p}=0.023$ \\
\hline & B.no & $53(29.4)$ & $50(27.8 \%)$ & \\
\hline & C.dont know & $35(19.4 \%)$ & $57(31.7 \%)$ & Significant \\
\hline \multirow[t]{6}{*}{4} & If you find signs of t.b whom do & & & \\
\hline & You consult & & & \\
\hline & A.astrologer & $22(12.2 \%)$ & $21(11.7 \%)$ & $\mathrm{X}^{2}=4.238, \mathrm{df}=3, \mathrm{p}=0.237$ \\
\hline & B.doctor & $138(76.7 \%)$ & $149(82.8 \%)$ & \\
\hline & C.priest & $1(0.6 \%)$ & $0(0 \%)$ & Not significant \\
\hline & D.dont know & $19(10.6 \%)$ & $10(5.6 \%)$ & \\
\hline
\end{tabular}

From table 1 it is seen that $64.4 \%$ of rural students considered $\mathrm{TB}$ as a severe disease compared to urban students $62.8 \%$ and the difference was found statistically significant.72.8\% urban students answered correctly that lungs are the most commonly affected organ and $85 \%$ were knowing that TB can occur among anyone including you and me, whereas only $47.2 \%$ of rural students were knowing about the correct affected organ and $76.1 \%$ were knowing about among whom it is commonly seen and the difference was found statistically highly significant.

Regarding causative agent $72.8 \%$ of rural students knew that TB is caused by bacteria whereas only $60 \%$ of urban students were aware about this and the difference was found statistically highly significant.
$56.7 \%$ of the rural students were knowing that TB spreds from person to person and $38.9 \%$ were knowing that TB is transmitted as droplet infection where as $48.3 \%$ of the urban students answered that TB spreads from person to person and $32.2 \%$ were knowing correctly about the mode of transmission and difference was found statistically not significant.

Table 2 shows that the rural students (78.9\%) were knowing correctly the symptoms of $\mathrm{Tb}$ compared to urban students(77.8\%) \& the difference was found statistically not significant, $52.8 \%$ of rural students were aware that $\mathrm{TB}$ is diagnosed by sputum examination compared to urban students $33.9 \%$ and it was found statistically highly significant. 
From the table 3 it is seen that $73.3 \%$ of urban students knew that TB can be cured completely compared to the rural students $68.3 \%$ and this difference was found statistically not significant. Regarding diagnosis and treatment $71.7 \%$ of the urban students were knowing that treatment is available in all the govt. hospitals including phcs compared to rural students $66.1 \%$ and the difference was found statistically highly significant, and $51.1 \%$ of urban students answered correctly that treatment of TB is completely free compared to rural students $40.6 \%$ and this difference was found statistically significant.82.8\% of the rural students told that they would consult the doctor if they find the signs of TB compared to urban students $76.7 \%$. This difference was found statistically not significant.

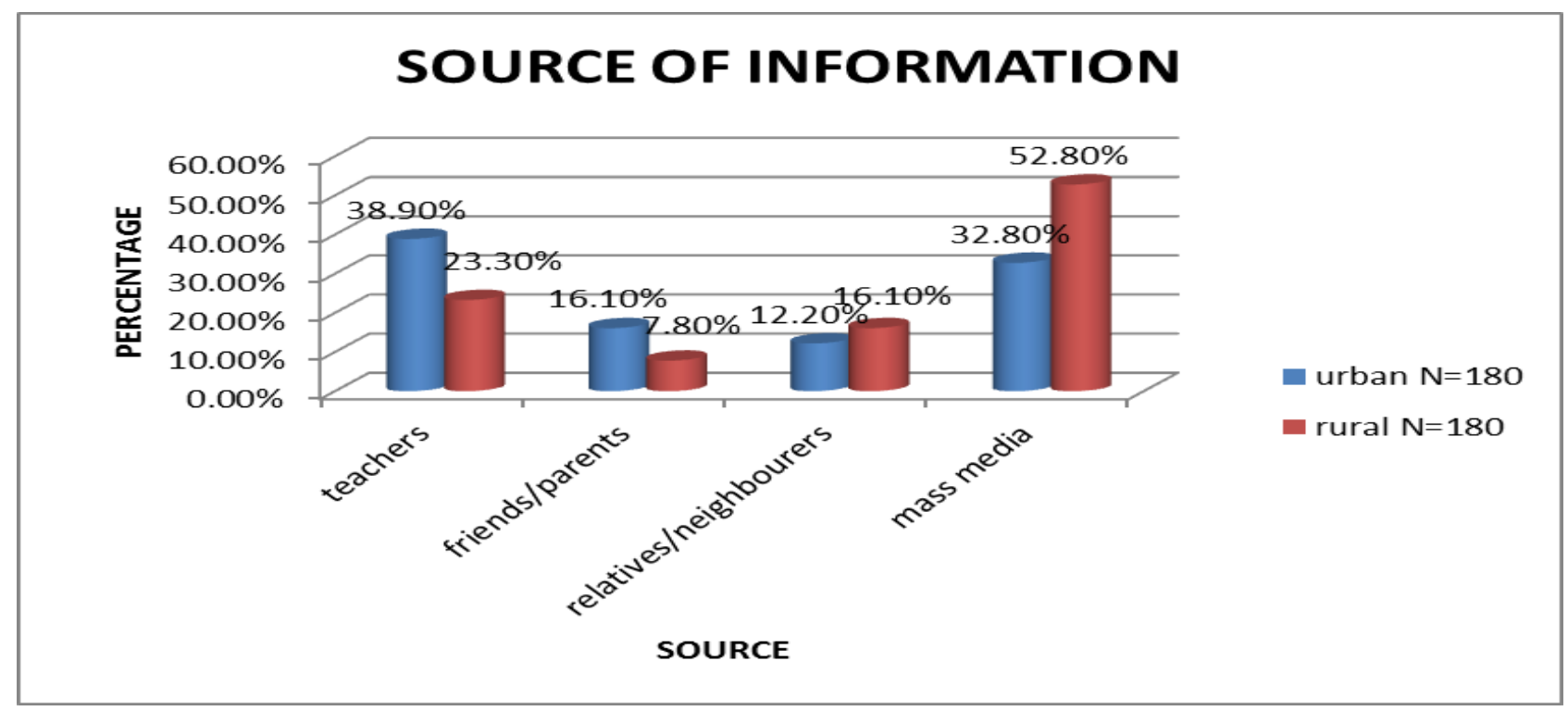

Figure 3: Source of information.

The table 4 shows that $85 \%$ of the urban students answered correctly that TB is prevented by covering the mouth and nose with cloth while coughing and sneezing and $86.1 \%$ of urban students answered they would advise the patient to complete the treatment, $90.6 \%$ of urban students told that they would encourage their friend to complete the treatment if they find their friend is diagnosed with TB as compared to rural students and all these differences were found statistically significant.

\section{DISCUSSION}

In the present study, assessment of Student's awareness about TB showed that the awareness of students is not satisfactory. The goal of national health policy 2002 was to increase the awareness of TB in both educated \& uneducated people. In 1959 the Government of India, with the help of WHO, established the National TB Institute (NTI) in Bangalore to develop a national TB control programmer (NTP), with the aim of establishing prompt awareness, diagnosis and ambulatory treatment which were integrated into general health services.

Our study showed that $72.8 \%$ urban \& $47.2 \%$ of rural students were aware that lungs are the most commonly affected organ and regarding causative agent $72.8 \%$ of rural \& $60 \%$ of urban students students were aware that TB is caused by bacteria/germ, $56.7 \%$ of the rural \&
$48.3 \%$ of the urban students were aware that TB spreads from person to person, $78.9 \%$ of the rural students were knowing correctly that cough with expectoration is the symptoms of $\mathrm{Tb}$ compared to urban students (77.8\%).Where as in a study done by Gopichandran V et al. $^{6}$ and Renuka $\mathrm{M}$ et $\mathrm{al}^{7}$ about $77 \%$ and $80.6 \%$ of the students were aware that tuberculosis is caused by bacteria and $85 \%$ and $85.3 \%$ were aware that it could spread from person to person. $80 \%$ and $78.3 \%$ of the students knew that cough for two weeks or more and weight loss were the common symptoms of tuberculosis and $76.4 \%$ and $83.7 \%$ of students were aware that lungs are the most commonly affected organ and in a study done by U.P Singh et al4 $70 \%$ of urban and rural males and females were aware that tuberculosis is caused by germs.

In our study $38.9 \%$ of urban $\& 32.2 \%$ of rural students was aware that TB is transmitted as droplet infection. It is seen in a study done by Tanimowo MO8 in Nigeria, on 791 senior secondary students; found that $70.9 \%$ of students answered correctly to the question- Can tuberculosis spread through air droplets? $71.6 \%$ answered correctly to question- Can it spread through overcrowding?

In our study $52.8 \%$ of rural students were aware that TB is diagnosed by sputum examination compared to urban 
students $33.9 \%$, where as in a study done by U.P Singh et $\mathrm{al}^{4}$ knowledge about sputum examination and chest skiagram as diagnostic tools was present in $42-48 \%$ and $31-35 \%$ students respectively and in a study done by Gopichandran $\mathrm{V}$ et $\mathrm{al}^{6}$ and Renuka $\mathrm{M}$ et $\mathrm{al}^{7} 52 \%$ and $72.1 \%$ were aware that the sputum test was the diagnostic test of choice.

In our study we have seen that $73.3 \%$ of urban students were knowing that TB can be cured completely compared to the rural students $68.3 \%$ where as in a study done by U.P. Singh et al4 on school children between 9th and 12 th standard, found that $31.62 \%$ of urban and $35.65 \%$ of rural students were aware that tuberculosis is curable and in study done by Renuka $\mathrm{M}$ et $\mathrm{al}^{7} 86 \%$ of students were aware that TB is curable.

In our study $51.1 \%$ of urban students answered correctly that treatment of TB is completely free compared to rural students $40.6 \%$, where as in a study done by Gopichandran $\mathrm{V}$ et $\mathrm{al}^{6}$ and Renuka $\mathrm{M}$ et $\mathrm{al}^{7} 71.9 \%$ and $81.4 \%$ of students answered correctly that treatment for tuberculosis is free of cost. In our study $85 \%$ of the urban students answered correctly that $\mathrm{TB}$ is prevented by covering the mouth and nose with cloth while coughing and sneezing compared to rural students $72.8 \%$, where as in a study done by Gopichandran $\mathrm{V}$ et $\mathrm{al}^{6}$ and Renuka $\mathrm{M}$ et $\mathrm{al}^{7} 74.5 \%$ and $94.6 \%$ of students answered correctly that tuberculosis is preventable.

Many studies have revealed that a lot of awareness and knowledge is still required among the students of schools and colleges. Inspite of the advertisement through media, pamphlet, banners on public places, and the awareness of students were not satisfactory. Therefore, the central and state Government and principals of school \& colleges must uplift some new steps in increasing the awareness of DOTS, methods of treatment, transmission and detection of TB.

\section{CONCLUSION}

Our study included a total of 360 students both from urban \& rural P.U colleges of Davangere taluk. Our study findings indicated that Teachers $(39 \%)$ were the most common source of information about T.B for urban students, where as for rural students Mass media (53\%) was the common source of information. Most of the urban $(63 \%) \&$ rural (64\%) students were aware that T.B is a serious disease. Awareness about which organ is affected,who are affected, diagnosis, Can T.B be cured completely, place of availability of treatment $\&$ diagnosis ,treatment \& diagnosis is free of cost, how to prevent \& advice to T.B patient, advice to friend with TB was better among urban students when compared to rural students, where as awareness regarding severity, causative agent, Mode of transmission, Spread from person to person, symptoms \& whom to consult if diagnosed with T.B was better among rural students compared to urban students. Overall the awareness was better among urban students compared to rural students \& $53 \%$ of the rural students had wrong knowledge that TB can be diagnosed by blood test.

\section{ACKNOWLEDGEMENTS}

I sincerely thank the institution, the principal and prof and head of the department of community medicine, principals and students of PU colleges of urban and rural area of Davangere taluk for their cooperation in carrying out the study. I also thank the teaching staff and my colleagues for their valuable guidance.

\section{Funding: No funding sources}

Conflict of interest: None declared

Ethical approval: The study was approved by institutional ethical committee of JJM Medical College Davangere, Karnataka

\section{REFERENCES}

1. Jagota, P., 2002: Revised National T.B. Control programme .Ind. J. Tub: 49-69.

2. Gopichandran V, Roy P, Sitaram A, karthick, John KR. Impact of a simple educational intervention on the knowledge of tuberculosis among high school children in Vellore, India. Indian J Comm Med 2010; 35:174-5.

3. Park K. Park's text book of Preventive Social Social Medicine. 21st edition.Jabalpur; Banarsidas Bhanot; Chapter 5, Respiratory infections: 165 .

4. Sing UP, Bala A, Goel RKD. Knowledge about Tuberculosis in senior school students of Punjab. Indian journal of community medicine. 2006;31(2):93-5.

5. Bhatt CP, Bhatt AB, Shrestha B .Nepalese People's Knowledge about Tuberculosis. SAARC J.TUBER. LUNG DIS.HIV/AIDS 2009;VI(2):31-7.

6. Gopichandran V, Roy P, Sitaram A, Karthick, John KR. Impact of a simple educational intervention on the knowledge and awareness of tuberculosis among high school children in Vellore, India. Indian $\mathbf{J}$ Community Med. 2010;35:174-6.

7. M. Renuka, Murali Dhar. Knowledge and Awareness of Tuberculosis among High School Students of Mysore City. Al Ameen J Med Sci. 2012;5(3):333-6.

8. Tanimowo MO. Knowledge, attitudes and practices regarding tuberculosis among senior secondary school students. East Afr Med J. 1999;76:47-ram (RNTCP): DOTS stratergy including DOTS plus:231.

Cite this article as: Shedole DT, Devalgi SB, Vidya GS, Mendagudli RR, Kumar VB. A comparative study on awareness about tuberculosis among urban and rural P.U college students of Davangere taluk, Karnataka, India. Int J Community Med Public Health 2015;2:552-7. 